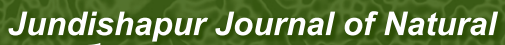 Pharmaceutical Products

\section{Chemical Composition and Antifungal Activity of Cuminum cyminum L. Essential Oil From Alborz Mountain Against Aspergillus species}

\author{
Hossein Mohammadpour ${ }^{1}$, Eskandar Moghimipour ${ }^{2}$, Iraj Rasooli ${ }^{3}$, Mohammad Hadi \\ Fakoor ${ }^{1,4^{*}}$, Shakiba Alipoor Astaneh ${ }^{3}$, Sara Shehni Moosaie ${ }^{1}$, Zeynab Jalili ${ }^{1}$ \\ ${ }^{1}$ Department of Microbiology, Masjed Soleiman Branch, Islamic Azad University, Masjed Soleiman, IR Iran \\ ${ }^{2}$ Medicinal Plant Research Center, Ahvaz Jundishapur University of Medical Sciences, Ahvaz, IR Iran \\ ${ }^{3}$ Department of Biology, Shahed University, Tehran, IR Iran \\ ${ }^{4}$ Department of Microbiology, Hidaj Branch, Islamic Azad University, Hidaj, IR Iran
}

\section{A R T I C L E I N F O}

Article type:

Original Article

Article history:

Received: 15 Nov 2011

Revised: 07 Feb 2012

Accepted: 29 Feb 2012

Keywords:

Oils

Cminum cyminum $\mathrm{L}$.

Antifungal Agents

Aspergillus spp.

\begin{abstract}
A B S T R A C T
Background: Aflatoxin $\mathrm{B}_{1}\left(\mathrm{AFB}_{1}\right)$ is a highly toxic and hepatocarcinogenic metabolite produced by Aspergillus species. Some natural products are known to kill fungi and destroy toxins and toxin-producing agents.

Objectives: The purpose of this study is to provide experimental data on the antifungal activity of cumin oils and their components that could be considered suitable for application in foods and drugs.

Materials and Methods: The essential oil (EO) of Cuminum cyminum L. collected from Alborz Mountain, Iran, was obtained by hydro-distillation. The oil was analyzed by gas chromatography (GC) and chromatography/mass spectrophotometry (GC/MS). The antifungal activity of the oil was studied with regard to the inhibition of the growth of Aspergillus flavus PICC-AF39, Aspergillus flavus PICC-AF24, Aspergillus parasiticus NRRL-2999 and Aspergillus niger. The minimal inhibitory (MIC) and minimal fungicidal (MFC) concentrations of the oil were determined.

Results: $\alpha$-Pinene (29.2\%), limonene (21.7\%), 1,8-cineole (18.1\%), linalool (10.5\%), linalyl acetate (4.8\%), and $\alpha$-terpineole (3.17\%) were the major components of the essential oil from C. cyminum L., and the oil showed a strong inhibitory effect on fungal growth.

Conclusions: Essential oils could be safely used as preservatives in pharmaceuticals as well as health and food products to protect them against toxigenic fungal infections.
\end{abstract}

Copyright $\odot 2012$ DocS

-Implication for health policy/practice/research/medical education:

The implication of this study is in Antifungal therapeutics.

\section{- Please cite this paper as:}

Mohammadpour H, Moghimipour E, Rasooli I, Fakoor MH, Alipoor Astaneh S, Shehni Moosaie S, Jalili Z. Chemical Composition and Antifungal Activity of Cuminum cyminum L. Essential Oil From Alborz Mountain Against Aspergillus species. Jundishapur J Nat Pharm Prod. 2012:7(2);50-5.

\footnotetext{
* Corresponding author: Mohammad Hadi Fakoor, Department of Microbiology, Masjed Soleiman Branch, Islamic Azad University, P.O. Box 6491796581 Masjed Soleiman, IR Iran and Department of Microbiology, Hidaj Branch, Islamic Azad University, P.O. Box 457158161 Hidaj, IR Iran. Tel.: +98 9124617814, Email: hadi.fakoor@gmail.com Copyright $\odot 2012$ DocS
}

\section{Background}

Aspergillus flavus, Aspergillus parasiticus, and Aspergillus nomius are able to produce aflatoxins. A. flavus produces only $B$ aflatoxins. Aflatoxin $B_{1}\left(A_{F} B_{1}\right)$ is the most potent carcinogen known in mammals, the risk assessment of which is well established $(1,2)$. Medicinal plants and spices have been used for generations by humans as food condiments and also to treat ailments because they are less toxic and generally free from side effects. Cuminum 
cyminum, which is a popular spice that is used as a flavoring agent, is widely used in food (3). The cumin seeds Cuminum cyminum L. belong to the family Apiaceae and are consumed in large quantities by Indians. Cumin is widely used in medicine for the treatment of dyspepsia, diarrhea, and jaundice, as it has stomachic, diuretic, carminative, and antispasmodic properties (4). China is an important exporter of this commodity and also uses it in traditional medicine. The use of natural antimicrobial compounds is important in the control of human and plant diseases of microbial origin (5). Many natural compounds have been identified that have antimicrobial activity (6-8), including essential oils (9).

\section{Objectives}

In this study, we identified the chemical composition and evaluated the antifungal properties of the essential oil of Cuminum cyminum L. from Alborz Mountain.

\section{Materials and Methods}

\subsection{Plant Material and Oil Extraction}

The plant (Cuminum cyminum L.) was collected from the Alborz mountain of Iran during June 2010. The seeds of the plant were used. The plant materials were hydro-distilled for $90 \mathrm{~min}$ in a full glass apparatus. The oils were extracted using a Clevenger-type apparatus. The extraction was performed after a 4-hour maceration in 500 $\mathrm{ml}$ of water. The oils were stored in dark glass bottles in a freezer at $-12{ }^{\circ} \mathrm{C}$ until they were used. The oil yield was approximately $1 \%$.

\subsection{Oil Analysis}

GC analyses were performed using a Shimadzu-9A gas chromatograph equipped with a flame ionization detector, and quantitative analysis was performed using Euro Chrom 2000 software from Knauer via the area normalization method, neglecting response factors. The analysis was performed using a DB-5 fused-silica column (30 m×0.25 mm, film thickness $0.25 \mu \mathrm{m}$, J \& W Scientific Inc., Rancho Cordova, CA, USA). The operating conditions were as follows: injector and detector temperature, 250 ${ }^{\circ} \mathrm{C}$ and $265{ }^{\circ} \mathrm{C}$, respectively; carrier gas, helium. The oven temperature program was $40{ }^{\circ} \mathrm{C}-250{ }^{\circ} \mathrm{C}$ at a rate of $4{ }^{\circ} \mathrm{C} /$ min. The GC/MS unit consisted of a Varian Model 3400 gas chromatograph coupled to a Saturn II ion trap detector. The column was the same as in GC, and the GC conditions were as described above. The mass spectrometer conditions were: ionization potential $70 \mathrm{eV}$; electron multiplier energy $2000 \mathrm{~V}$. The identities of the oil components were established from their GC retention indices, relative to C7-C25 n-alkanes, by comparison of their MS spectra with those reported in the literature $(10,11)$, and by computer matching with the Wiley 5 mass spectra library, whenever possible, upon co-injection with standards available in the laboratories.

\subsection{Fungal Strains and Cultures}

The microorganisms used were Aspergillus flavus PICCAF39, Aspergillus flavus PICC-AF24, Aspergillus parasiticus NRRL-2999, and Aspergillus niger. All of these microorganisms are highly toxic and were maintained on Sabouraud Dextrose Agar (Merck, Germany) at $4{ }^{\circ} \mathrm{C}$. Spore suspensions were prepared and diluted in sterile yeast extract sucrose (YES) broth to a concentration of approximately $10^{6} \mathrm{spores} / \mathrm{ml}$. The spores were counted using a hemocytometer. Subsequent dilutions were made from the above suspension and then used in the tests.

\subsection{Antifungal Analysis}

The minimal inhibitory concentration (MIC), minimal fungicidal (MFC) concentration, and fungicidal kinetics of the oils were determined. The disc diffusion method was used for antifungal screening as follows: Sterile Sabouraud Dextrose Agar (Merck) was inoculated with Aspergillus flavus PICC-AF39, Aspergillus flavus PICC-AF24, Aspergillus parasiticus NRRL-2999, and Aspergillus niger spores $\left(10^{6}\right.$ spores $\left./ \mathrm{ml}\right)$ and distributed into petri plates with a diameter of $80 \mathrm{~mm}$. Sterile 6-mm Whatman No. 1 filter paper was used as the disc. Under aseptic conditions, the discs were placed on the agar plates and then $5 \mu 1,10$ $\mu \mathrm{l}$, and $20 \mu \mathrm{l}$ of each of the oils was put on the discs. The plates were incubated at $28 \pm 2{ }^{\circ} \mathrm{C}$ for 20 days. Three replicates were used for each treatment. The diameter of the microbial inhibition zones was measured using vernier calipers. The percent mycelia inhibition was calculated by the equation: $I=1-T / C \times 100$, where $I$ is the inhibition (\%), C is the colony diameter of mycelium from a control petri plate $(\mathrm{mm})$ and $\mathrm{T}$ is the colony diameter of mycelium from a test petri plate (mm) (11). The MIC and MFC (12) were determined by the broth dilution method in test tubes as follows: Various concentrations of the oils were added to $5 \mathrm{ml}$ of YES broth tubes containing $10^{6}$ spores/ $\mathrm{ml}$. The tubes were then incubated on an incubator shaker to evenly disperse the oil throughout the broth in the tubes. The highest dilution (lowest concentration) that showed no visible growth was regarded as the MIC. Cells from the tubes showing no growth were subcultured on Sabouraud Dextrose Agar plates to determine whether the inhibition was reversible or permanent. The MFC was determined as the highest dilution (lowest concentration) at which no growth occurred on the plates.

\subsection{Fungicidal Kinetics of Cuminum cyminum $L$.}

Cuminum cyminum oil from Alborz Mountain at the MFC dilution was added to $5 \mathrm{ml}$ of spore suspension tubes containing $10^{6}$ spores $/ \mathrm{ml}$ in triplicate and then incubated at $28 \pm 2{ }^{\circ} \mathrm{C}$ in an incubator shaker. Samples taken after 0 , 
$4,8,12,16,20$, and 24 hours were cultured on Sabouraud Dextrose Agar plates for $48 \mathrm{~h}$ at $28 \pm 2{ }^{\circ} \mathrm{C}$. The control tubes had no essential oil added. Fungal colonies were counted after incubation period, and the total number of viable spores per $\mathrm{ml}$ was calculated (13).

\section{Results}

The results obtained by the GC and GC-MS analyses of the essential oils of C. cyminum L. from the Alborz Mountain range of Iran are presented in Table 1. Twenty-eight compounds were identified in the essential oil of $C$. cyminum L from Alborz Mountain. GC and GC-MS analyses revealed that $C$. cyminum L. from Alborz mountain contained $\alpha$-pinene (29.2\%), limonene (21.7), 1,8-cineole (18.1\%), linalool (10.5\%), and $\alpha$-terpineole (3.17) as the major compounds. The oil yield was approximately $1 \%$. The antifungal activities of the C. cyminum L. essential oil against Aspergillus flavus PICC-AF39, Aspergillus flavus PICC-AF24, Aspergillus parasiticus NRRL-2999, and Aspergillus niger were qualitatively and quantitatively assessed according to the inhibition zone diameter as well as the MIC and MFC values (Tables 2 and 3). The essential oil had substantial antifungal activity against the four fungal species tested. The four fungi species exhibited high diameters of growth inhibition $(35,55,37$ and $38 \mathrm{~mm})$. At a dose of $10 \mu \mathrm{l}$ of the oil per disc per petri plate, the C. cyminum $\mathrm{L}$. essential oil was particularly effective against Aspergillus parasiticus NRRL-2999, Aspergillus niger, Aspergillus flavus PICC-AF24, and Aspergillus flavus PICC-AF39 with diameters of inhibition of approximately 25, 35, 23 and 23 $\mathrm{mm}$, respectively, on the second day of incubation. At the end of thirtieth day, the diameter of inhibition was approximately 13, 9, 12, and $13 \mathrm{~mm}$ for Aspergillus parasiticus NRRL-2999, Aspergillus niger, Aspergillus flavus PICC-AF24, and Aspergillus flavus PICC-AF39 respectively. With a dose of $20 \mu \mathrm{l}$ of the oil per disc per petri plate, the diameter of inhibition for Aspergillus parasiticus NRRL-2999, Aspergillus niger, Aspergillus flavus PICC-AF24, and Aspergillus flavus PICC-AF39 was 12, 17, 17, and $14 \mathrm{~mm}$, respectively (Table 2). The antifungal activity was expressed as the MIC and MBC values (Table 3). The C. cyminum L. oil killed more than 60\%

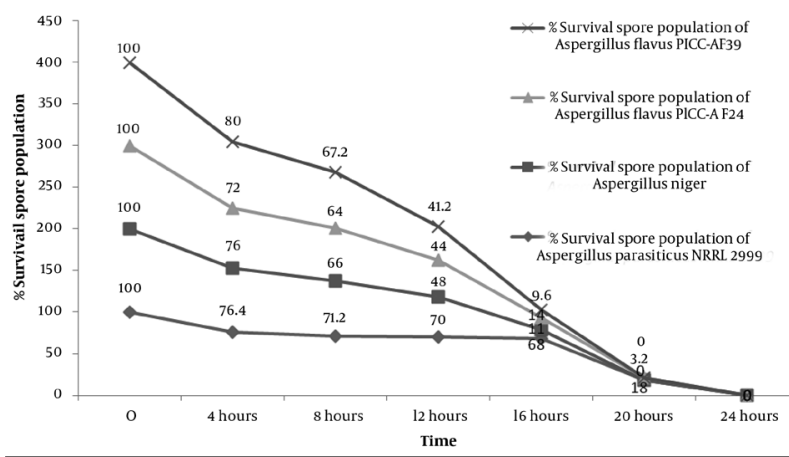

Figure 1. Kinetics of Aspergillus Spore Destruction at Minimal Fungicidal Concentrations (MFC) of the Fresh Essential Oil From Cuminum cyminum L. Initial Spore Concentration:106/ml. of the spores of the four Aspergillus species tested within 12 hours. In Aspergillus flavus PICC-AF39 and Aspergillus niger, $100 \%$ lethality was observed within 20 hours of the exposure to the oil, whereas $100 \%$ of Aspergillus flavus PICC-AF24 and Aspergillus parasiticus NRRL-2999 spores died after 24 hours. Figure 1 shows that the spore death occurred in the first 24 hours.

\section{Discussion}

The main components of essential oils are reported to be different. Different combinations of C. cyminum L. have been reported previously (14-18).

The main oil components were cumin-alcohol (24.4\%), 2-caren-10-al (20.9\%), cuminal (18.4), and $\gamma$-terpinen (10.6) for C. cyminum from China (18). The major components reported by Lu Wang et al. (2009) included cuminal, cuminalcohol, p-cymene, $\beta$-pinene, 2-care-10-al, and $\gamma$-terpinene at $22.76 \%, 21.76 \%, 14.33 \%, 11.06 \%, 8.56 \%$, and $7.05 \%$, respectively (16). In addition, the three major compounds

Table 1. Chemical Composition of Cuminum cyminum L. Essential Oil From Alborz Mountain of Iran

\begin{tabular}{|c|c|c|c|}
\hline No. & Alborz Mountain & $\mathbf{R I}^{\mathbf{a}}$ & $\%^{\mathbf{b}}$ \\
\hline 1 & Isobutyl isobutyrate & 892 & 0.8 \\
\hline 2 & $\alpha$-Thujene & 922 & 0.3 \\
\hline 3 & $\alpha$-Pinene & 931 & 29.2 \\
\hline 4 & Sabinene & 971 & 0.6 \\
\hline 5 & Myrcene & 981 & 0.2 \\
\hline 6 & p-Cymene & 1013 & 0.3 \\
\hline 7 & Limonene & 1025 & 21.7 \\
\hline 8 & 1,8-Cineole & 1028 & 18.1 \\
\hline 9 & $\gamma$-Terpinene & 1051 & 0.6 \\
\hline 10 & Terpinolene & 1082 & 0.3 \\
\hline 11 & Linalool & 1089 & 10.5 \\
\hline 12 & $\alpha$-Campholenal & 1122 & 0.03 \\
\hline 13 & trans-Pinocarveole & 1130 & 0.07 \\
\hline 14 & $\delta$-Terpineole & 1154 & 0.09 \\
\hline 15 & Terpinene-4-ol & 1169 & 0.5 \\
\hline 16 & $\alpha$-Terpineole & 1180 & 3.17 \\
\hline 17 & trans-Carveole & 1213 & 0.4 \\
\hline 18 & cis-Carveole & 1217 & 0.07 \\
\hline 19 & Geraniol & 1242 & 1.1 \\
\hline 20 & Linalyl acetate & 1248 & 4.8 \\
\hline 21 & Methyl geranate & 1310 & 0.2 \\
\hline 22 & $\alpha$-Terpinyl acetate & 1342 & 1.3 \\
\hline 23 & Neryl acetate & 1351 & 0.09 \\
\hline 24 & Methyl eugenol & 1369 & 1.6 \\
\hline 25 & $\beta$-Caryophyllene & 1430 & 0.2 \\
\hline 26 & Spathulenol & 1562 & 0.07 \\
\hline 27 & Humulene epoxide II & 1608 & 0.08 \\
\hline 28 & Acetocyclohexane dione (2) & 1704 & 0.4 \\
\hline
\end{tabular}

${ }^{a}$ Retention Index Relative to n-alkane Series on the DB-5 Column.

${ }^{\mathrm{b}}$ Percentage Composition of the C. cyminum L. Essential Oil. 


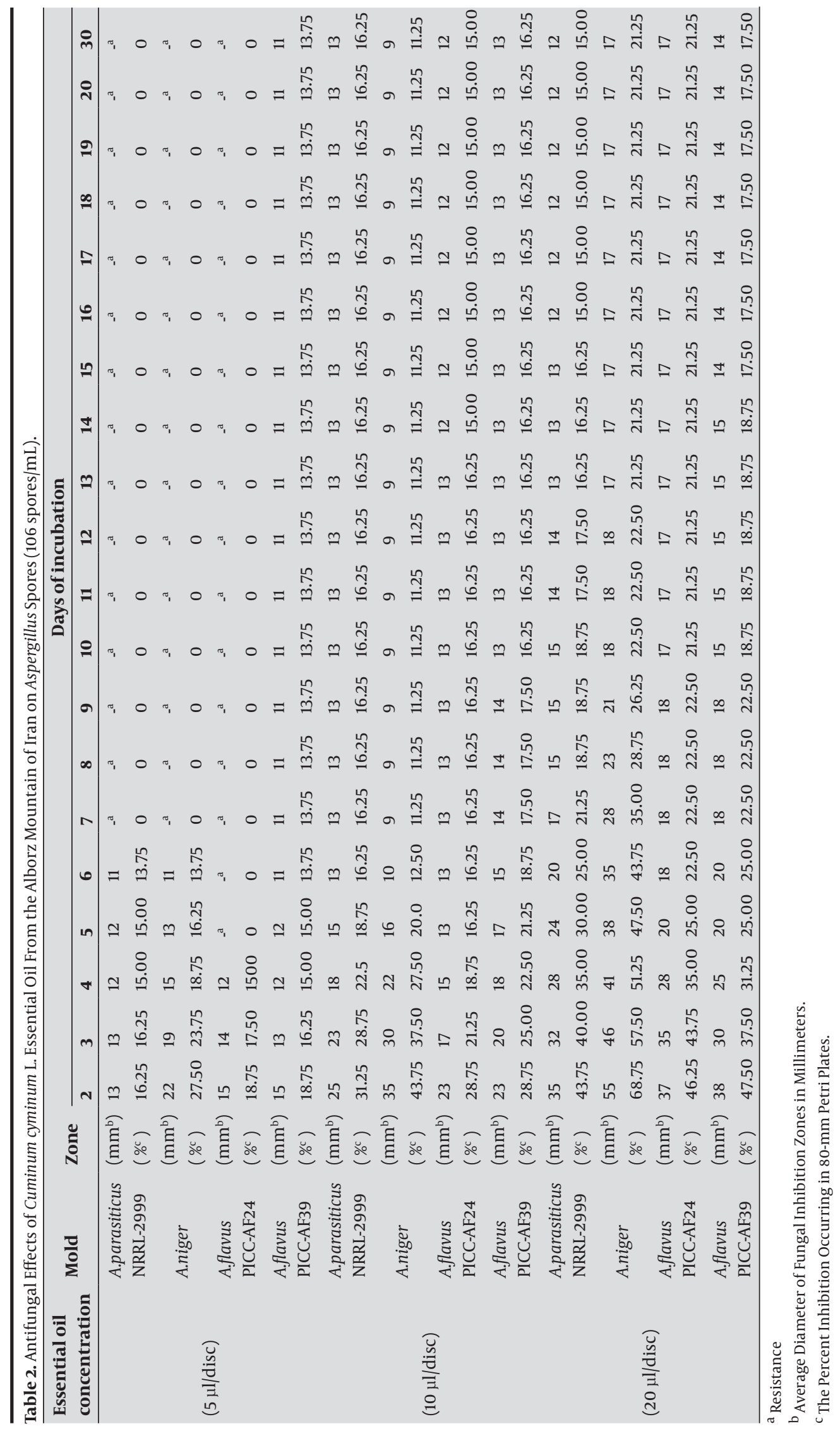


Table 3. Minimal Inhibitory Concentration (MIC) and Minimal Fungicidal Concentration (MFC) (ppm) of the Cuminum cyminum L. Essential Oil From the Alborz Mountain of Iran Against Aspergillus Species Spores (106 spores/ml).

\begin{tabular}{lll}
\hline Mold & MIC $^{\mathbf{a}}$ & MFC $^{\mathbf{a}}$ \\
\hline Aspergillus parasiticus NRRL-2999 & $750 \mathrm{ppm}$ & $3000 \mathrm{ppm}$ \\
Aspergillus niger isolated from food sample & $1000 \mathrm{ppm}$ & $3000 \mathrm{ppm}$ \\
Aspergillus flavus PICC-AF24 & $1000 \mathrm{ppm}$ & $3000 \mathrm{ppm}$ \\
Aspergillus flavus PICC-AF39 & $1000 \mathrm{ppm}$ & $2500 \mathrm{ppm}$ \\
\hline
\end{tabular}

a Abbreviations: MIC: Minimal Inhibitory Concentration; MFC: Minimal Fungicidal Concentration

obtained by Ziming Wang et al. (2006) in China were cuminal (45.75\%), $\alpha$-proyl-benzenemethanol (14.76\%), and 2-ethylidene-3,5-heptadienal (12.91) (17). In the essential oil characterized by Rebey et al. (2012) from Tunisia, the major compounds were $\gamma$-terpinen (25.58\%), 1-phenyl-1,2 ethanediol (23.16\%), cuminaldheyde (15.31\%), $\beta$-pinene (15.16\%), and p-cymene (9.05\%)(15). Nineteen compounds were identified in the essential oil of C. cyminum L. from Mashhad, Iran (Oroojalian et al. 2010), and the main components were cuminaldehyde (30.2\%), p-cymene (14.1\%), $\gamma$-terpinene (12.8\%), safranal (9.4\%), and $\beta$-pinene $(6.4 \%)$ (19). Our analysis of C. cyminum L. from the Alborz mountain identified $\alpha$-pinene (29.2\%), limonene (21.7\%), 1, 8-cineole (18.1\%), linalool (10.5\%), and $\alpha$-terpineole (3.17\%) as the major compounds. Twenty-eight compounds were identified in the essential oil of C. cyminum $L$.

In all cases, hydro-distillation was applied to extract the essential oil from C. cyminum L., and the extracts were analyzed by GC and GC/MS. Cumin oil possesses various compounds at different concentrations in different regions. These differences in the chemical composition of the oils could be attributed to many factors, including plant part, harvest time, extraction method, type of cultivar, storage conditions, climatic effects on the plants, and geographic origin (14-19). The oil yield in the present study was approximately $1 \%$. The essential oil yield of cumin seeds from a local market in India was reported to be $2.33 \%(20)$. C. cyminum L. from the Alborz mountain had good antifungal activity against the four fungi species tested. This study indicates that $C$. cyminum $L$. has considerable anti-Aspergillus activity and thus deserves further investigation for clinical applications. Antimicrobial activity of $C$. cyminum L. has been reported against Gram-positive and Gram-negative bacterial species as well as yeast strains $(19,21,22)$. The antibacterial effects of the EOs were assessed for several food-borne pathogens, namely Staphylococcus aureus, Bacillus cereus, Escherichia coli O157:H7, Salmonella enteritidis, and Listeria monocytogenes. The MIC and MBC of the essential oil were within the range of 0.37 to $3 \mathrm{mg} / \mathrm{ml}$ for C. Cyminum L. (19) Iacobellis, Cantore, Capasso, and Senatore (2005) reported moderate antibacterial activity of $C$. cyminum L. against some bacterial plant pathogens (22). Although the antifungal activity of C. Cyminum is obvious, the mechanism of action remains unclear. Further research is recommended to identify the mechanisms.

\section{Acknowledgments}

This study was fully supported by the Vice Chancellor for Research affairs of Azad University, Masjed Soleiman Unit. The authors also wish to express their gratitude to Mr. Alireza Gafari for his technical assistance.

\section{Financial Disclosure}

None declared.

\section{Funding/Support}

None declared.

\section{References}

1. Diener UL, Davis ND. Aflatoxin production by isolates of Aspergillus flavus. Phytopathology. 1966;56(12):1390-3.

2. Hussein HS, Brasel JM. Toxicity, metabolism, and impact of mycotoxins on humans and animals. Toxicology. 2001;167(2):101-34.

3. Li R, Jiang ZT. Chemical composition of the essential oil of Cuminum cyminum L. from China. Flavour Fragrance J. 2004;19(4):3113.

4. Dhandapani S, Subramanian VR, Rajagopal S, Namasivayam N. Hypolipidemic effect of Cuminum cyminum L. on alloxan-induced diabetic rats. Pharmacol Res. 2002;46(3):251-5.

5. Baratta MT, Dorman H, Deans SG, Figueiredo AC, Barroso JG, Ruberto G. Antimicrobial and antioxidant properties of some commercial essential oils. Flavour and fragrance journal. 1998;13(4):235-44.

6. Fakoor M, Pipelzadeh MH. A study on the healing effect of honey on infected open fracture wounds. Pakistan J Med Sci. 2007;23(3):327.

7. Nguefack J, Leth V, Amvam Zollo PH, Mathur SB. Evaluation of five essential oils from aromatic plants of Cameroon for controlling food spoilage and mycotoxin producing fungi. Int J Food Microbiol.2004;94(3):329-34.

8. Weckesser S, Engel K, Simon-Haarhaus B, Wittmer A, Pelz K, Schempp CM. Screening of plant extracts for antimicrobial activity against bacteria and yeasts with dermatological relevance. Phytomedicine. 2007;14(7-8):508-16.

9. Soliman KM, Badeaa RI. Effect of oil extracted from some medici nal plants on different mycotoxigenic fungi. Food Chem Toxicol. 2002;40(11):1669-75.

10. Davies N. Gas chromatographic retention indices of monoterpenes and sesquiterpenes on methyl silicone and Carbowax 20M phases. J Chromatogr. 1990;503(1):1-24.

11. Rasooli I, Fakoor MH, Yadegarinia D, Gachkar L, Allameh A, Rezaei MB. Antimycotoxigenic characteristics of Rosmarinus officinalis and Trachyspermum copticum L. essential oils. Int J Food Microbiol. 2008;122(1-2):135-9.

12. Rasooli I, Mirmostafa SA. Bacterial susceptibility to and chemical composition of essential oils from Thymus kotschyanus and Thymus persicus. J Agric Food Chem. 2003;51(8):2200-5.

13. Rasooli I, Fakoor MH, Allameh AA, Rezaee MB, Owlia P. Phytoperevention of aflatoxin production. J Med Plants. 2009;8(5):97-104. 
14. Behera S, Nagarajan S, Jagan Mohan Rao L. Microwave heating and conventional roasting of cumin seeds (Cuminum cyminum L.) and effect on chemical composition of volatiles. Food Chem. 2004;87(1):25-9.

15. Bettaieb Rebey I, Jabri-Karoui I, Hamrouni-Sellami I, Bourgou S, Limam F, Marzouk B. Effect of drought on the biochemical composition and antioxidant activities of cumin (Cuminum cyminum L.) seeds. Ind Crops Prod. 2012;36(1):238-45.

16. Wang L, Wang Z, Zhang H, Li X. Ultrasonic nebulization extraction coupled with headspace single drop microextraction and gas chromatography-mass spectrometry for analysis of the essential oil in Cuminum cyminum L. Anal Chim Acta. 2009;647(1):72-7.

17. Wang Z, Ding L, Li T, Zhou X, Wang L, Zhang H, et al. Improved solvent-free microwave extraction of essential oil from dried Cuminum cyminum L. and Zanthoxylum bungeanum Maxim. J Chromatogr A. 2006;1102(1-2):11-7.

18. Zhang H, Shi Y, Wei S, Wang Y. Ultrasonic nebulization extraction coupled with headspace single-drop microextraction of volatile and semivolatile compounds from the seed of Cuminum cyminum L. Talanta. 2011;85(2):1081-7.

19. Oroojalian F, Kasra-Kermanshahi R, Azizi M, Bassami M. Phytochemical composition of the essential oils from three Apiaceae species and their antibacterial effects on food-borne pathogens. Food Chem. 2010;120(3):765-70.

20. Sowbhagya H, Sathyendra Rao B, Krishnamurthy N. Evaluation of size reduction and expansion on yield and quality of cumin (Cuminum cyminum) seed oil. J Food Eng. 2008;84(4):595-600.

21. Hajlaoui H, Mighri H, Noumi E, Snoussi M, Trabelsi N, Ksouri R, et al. Chemical composition and biological activities of Tunisian Cuminum cyminum L. essential oil: a high effectiveness against Vibrio spp. strains. Food Chem Toxicol. 2010;48(8-9):2186-92.

22. Iacobellis NS, Lo Cantore P, Capasso F, Senatore F. Antibacterial activity of Cuminum cyminum L. and Carum carvi L. essential oils. J Agric Food Chem. 2005;53(1):57-61. 